Indonesian Journal of Nutrition and Dietetics Vol. 6, No. 2, 2018: 70-76
Available online at: http://ejournal.almaata.ac.id/index.php/IJND DOI : http://dx.doi.org/10.21927/ijnd.2018.6(2).70-76

\title{
The effect of neonatal visit on exclusive breastfeeding
}

\author{
Chori Elsera
}

\author{
STIKES Muhammadiyah Klaten, Jawa Tengah, Indonesia \\ ${ }^{*}$ Corresponding author: chorielsera@gmail.com
}

\begin{abstract}
Background: Infant mortality rate in Indonesia was high approximately 22,23 per 1,000 live births (2016) and very far from the SDGs target by 2030 that was 12 per 1,000 live births. In the other hand, Indonesia ranked 10 out of 18 Southeast Asia Countries. The coverage of exclusive breastfeeding in Indonesia was still low and decreasing every year

Objectives: To determine the effect of neonatal visits on exclusive breastfeeding.

Methods: An case-control design was used. Participants were mothers whose babies aged 6 to 9 months who met the inclusion criteria. A total of 158 participants were divided into 2 groups, 79 in the case group and 79 in the control group. The sampling technique was a simple random sampling. Data were collected by interviews with questionnaires and secondary data. Analysis of the data used univariate analysis with frequency distribution table, bivariate analysis Chi-square test and multivariate analysis with logistic regression.

Results: Results showed $76.6 \%$ of participants were working mothers, 90.5\%, had higher education history. There was a significant relationship between a neonatal visit with exclusive breastfeeding $O R=0.48 ; 95 \% \mathrm{Cl} ; 0.26-0.92$. Extreme variables that most influences on exclusive breastfeeding were working with a value of $p=0.016$ (OR $2.87895 \% \mathrm{Cl} 1.217-6.805)$.

Conclusion: Neonatal Visit influenced exclusive breastfeeding. Whereas maternal employment is the most influential factor for exclusive breastfeeding.
\end{abstract}

KEYWORDS: exclusive breastfeeding, neonatal visit, maternal employment

\section{INTRODUCTION}

Neonatal morbidity and mortality have always been a matter of interest for discussion because it is a picture of the level of health care problems in a country. The high rate of infant mortality in certain areas indicate poor health status in the region, it is due to other causes of infant mortality between the level of antenatal care, nutritional status of pregnant women, the success rate of $\mathrm{MCH}$ and family planning programs, as well as environmental and socio-economic conditions. In Indonesia, the infant mortality rate is higher than other ASEAN countries, 4.6 times higher than in Malaysia, 1.8 times higher than in Thailand and 1.3 times higher than the infant mortality in the Philippines (1).

A variety of conditions can be a factor in infant mortality. Results of research conducted by Astuti 2007 showed that $39.8 \%$ of infant deaths due to complications from baby's temperature setting, $23.4 \%$ due to complications during pregnancy and during delivery, and $23.1 \%$ due to respiratory and cardiovascular disorders. The same study states that the neonatal mortality less than 24 hours age of approximately $78 \%$. Very high neonatal deaths occur in the first week of life of about $25-45 \%$ of all neonatal deaths (5)

The analysis of the study showed that the risk of neonatal infection disease increased 1.6 times in infants who did not receive neonatal visit in the first week. The risk of neonatal mortality increased 9.5 times in infants with low birth weight and 3.4 times in women with no education or did not complete primary school. The results showed that social factors (education and economics) associated with increased incidence of neonatal mortality (6),

Various measures were taken by the government to continue to reducing reduce infant mortality, one of them was a basic health service delivery to the community. Basic health services to the public quickly and accurately are expected to overcome most of the health problems. Policies on maternal and newborn such 
as antenatal care, childbirth, postpartum and newborn care are optimized from the primary neighborhood health center to government and private hospitals. Antenatal care set by the government at least 4 times during pregnancy while neonatal visits did 3 times (2). The government recommended antenatal care at last 4 times during pregnancy and 3 times neonatal visit

Indonesian health strategic plan targeted the number of neonatal first visit was $82 \%$ in 2010 , but Indonesian only reached $80 \%$. Twenty-five provinces in Indonesia have succeeded in achieving the strategic plan targets one of then was in Central Java that is equal to $98 \%$. Central Java Province have been to achieve the target of the strategic plan for the complete neonatal visits (3 visits neonates) in 2010 (91\%). In the same year, Central Java have been achieve the highest target in implementing the strategic planning of health services in the baby at least 4 times a year in the amount of $96.7 \%$. The achievement of a baby visit is influenced by the activity of primary health center which conducted every month, the active role of care and also family support to take the baby to the primary health center and can not be separated from the guidance and monitoring of local health (2).

Basic Health Risets (Riskesdas) which indicates the successnes of Central Java province in achieving the strategic plan targets neonatal visit coverage, visit complete neonates and infants visit coverage contrast with coverage of exclusive breastfeeding. Based Susenas 2009 there were $61.3 \%$ of infants at the age of $0-5$ months are exclusively breastfed at the lowest range between $48.8 \%$ to $78.3 \%$ (2). Meanwhile, based on 2012 figures IDHS (Indonesian Demography Health Survey / SDKI) coverage exclusively breastfed infants at the age of 0-5 months was $41.5 \%$ (IDHS, 2012). Central Java province is included in the lowest group for coverage of exclusive breastfeeding of $52.2 \%$ in 2010 , became $45.18 \%$ in 2011 and decreased again to $25.6 \%$ in 2012. The decline in coverage of exclusive breastfeeding in Java-Central is also probably related to an increase in infant mortality in Central Java (4).

Breast milk is the complete nutrition which every baby needs. Exclusive breastfeeding can prevent infant mortality by $13 \%$. The provision of complementary foods at the right time and the number of infant deaths can be prevented as much as $6 \%$ so that breastfeeding exclusively for 6 months followed by two years breastfeed with the appropriate complementary feeding can prevent infant mortality by $19 \%$ (7).

Breast milk has predominase primacy for the prevention of various diseases. The most effective prevention can be done as early as possible, starting from the age of zero days, with exclusive breastfeeding until of 6 months old for the formation of immune defense and then continued until the age of 2 years old. As presented by Khamzah, that breastfeeding can boost immunity breastfeeding a super food that irreplaceable even the most expensive formula, breastfeeding can reduce the incidence of infection in children, breastfeeding is essential for optimal growth and development, breastfeeding is able to prevent cancer in children, breastfeeding prevent cardiovascular disease, breast milk is able to reduce the incidence of Diabetes Mellitus, Breast milk is able to improve the intelligence of children, prevent allergies, and reduces the risk of cavities (8).

Looking at the data that is inversely proportional to the exposure of neonates visit coverage with coverage of exclusive breastfeeding in the Central Java Province and the lack of research on the relationship between neonatal visits and exclusive breastfeeding, researchers interested in conducting a study on the effects of neona. tal visits to exclusive breastfeeding in Klaten.

\section{MATERIALS AND METHODS}

Observasional study with, case-control design was used with a quantitative approach. The sample of in this study were mothers with babies aged 6 to 9 months at the time of the study that met the inclusion criteria. The total samples were 158 respondents, 79 in the case group and 79 in the control group. The sampling technique with simple random sampling. Hypothesis test using Chi-Square $\left(X^{2}\right)$ with 95\% Confidence Interval. Data collected interviewing with questionnaires and KIA book. Analysis of the data used univariate analysis with frequency distribution table, with Chi-square bivariate and multivariate logistic regression. Univariat data analysis with distribution frequency table, analysis bivariate with chi-square and logistic regression for multivariate.

The criteria of inclusion samples were mothers with babies aged 6 to 9 months identified by reports in 
each Primary Health Center and willing to participate in the study. Meanwhile exclusion criteria were mother whose babies born with major congenital abnormalities (e.g., hydrocephalus, tetralogy of Fallot, Anchepali etc) Identify all respondents into two groups, namely the exclusive breastfeeding (cases group) and not exclusive breastfeeding (controls group). In determining cases and controls carried out by identifying exclusive breastfeeding the answers of the respondents. The control group was more difficult to find than that was in the case group. In this study, the implementation of some 153 researchers collected data from the data group and 80 cases in the control group. Then the researchers matched by adjusting the case group and control group which eliminates the data of the cases were not matching. Matching in this study performed on confounding variables family support, knowledge and IMD. The data collection is done by filling in a questionnaire (primary data) and matched with the secondary data from KIA (Kesehatan Ibu \& Anak) book or document in local health services.

\section{RESULT}

The characteristic of participants indicated that most respondents either exclusively breastfed or not exclusively aged 24-35 years. Most respondents had a number of children $\leq$ less than two, ie by 62 respondents in the case group and the control group 64 respondents. Univariate analysis, showed that most mothers did not conduct a complete neonatal (48.1\%). Most of the educated mother up by $63.9 \%$. Based on the work of $76.6 \%$ of mothers did not work. Good knowledge about breastfeeding mothers at $90.5 \%$. Amounted to $60.1 \%$ of women give birth in hospitals. All the women helped by health workers during childbirth, which is $60.8 \%$ attended by midwives. $83.5 \% \%$ baby was born with a normal pregnancy. The baby's birth weight of $13.3 \%$ smaller abnormal birth weight (birth weight either small or large). Most families drop support for exclusive breastfeeding of (96.2\%) and most mothers do IMD (69.0\%) during childbirth.

Employment relationship with exclusive breastfeeding in the Table 1 shows a significant relationship with the value of Ods Ratio of $2.58(95 \% \mathrm{Cl}$ : 1.19 5.56). Mothers who did not work increased the risk of exclusive breastfeeding of 2.58 times greater than mothers who work either at home or outside the home, earn income and leave the baby more than two hours. Gestational age at birth affects exclusive breastfeeding, in Table 1. shows the value of $\mathrm{OR}=0.32$; $95 \% \mathrm{Cl} ; 0,16-0$. Normal gestational age (37-40) weeks of exclusive breastfeeding increased the chance of 0.38 times compared with abnormal gestational age, but the relationship is not significant.

The baby's birth weight have a significant relationship with exclusive breastfeeding as indicated by the value of $p=0.00$ OR 0.13 (95\% Cl: 0.04 to 0.48 ). Results showed that babies born with normal weight (2500-3999 grams) have increase the risk of 0.13 occurrence of exclusive breastfeeding.

High education level at least high school graduates do not have a statistically significant association with exclusive breastfeeding $\mathrm{OR}=0.68 ; 95 \% \mathrm{Cl}$; 0.32 1.17. Education can increased the risk of exclusive breastfeeding was 0.6 times compared with the level of primary education, but the relationship is not significant.

Mother's knowledge about exclusive breastfeeding mothers had no meaningful relationship whith exclusive breastfeeding, OR=1.16; $95 \% \mathrm{Cl} ; 0.40$ - 3.37.

Place of birth, birth attendants, and IMD( Inisiasi Menyusu Dini) does not have a significant relationship to exclusive breastfeeding. Thus births in hospitals increased the risk by 0.85 times greater and births attended by physicians increased the risk by 0.58 times more likely to breastfeed exclusively compared with deliveries in BPS or health center and attended by midwives.

\section{Table 2. Logistic Regression Analysis Between Neonatal Visits, Education, Employment, Knowledge, Place of Birth, Birth Attendants, Gestational Age, Birth Weight, Family Support and Breastfeeding Initiation on Exclusive Breastfeeding in Klaten}

\begin{tabular}{lccc}
\hline \multicolumn{1}{c}{ Variable } & $\boldsymbol{p}$ & OR & Cl 95\% \\
\hline Neonates Visit & 0.02 & 0.43 & $0.21-0.88$ \\
Education & 0.09 & 0.52 & $0.25-1.10$ \\
Working & 0.02 & 2.88 & $1.22-6.81$ \\
Knowladge & 0.48 & 1.57 & $0.46-5.40$ \\
Place of Birth & 0.92 & 0.95 & $0.36-2.54$ \\
Birth Assist & 0.35 & 0.63 & $0.24-1.66$ \\
Gestasi Age & 0.50 & 1.56 & $0.43-5.69$ \\
Birth Weight & 0.00 & 0.08 & $0.02-0.43$
\end{tabular}


Table 1. Analysis of factors affecting exclusive breastfeeding

\begin{tabular}{|c|c|c|c|c|c|c|c|}
\hline \multirow{3}{*}{ Variable } & \multicolumn{4}{|c|}{ Exclusive Breastfeeding } & \multirow{3}{*}{$p$} & \multirow{3}{*}{ OR } & \multirow{3}{*}{ Cl $95 \%$} \\
\hline & \multicolumn{2}{|c|}{ Yes } & \multicolumn{2}{|c|}{ No } & & & \\
\hline & $\mathbf{n}$ & $\%$ & $\mathbf{n}$ & $\%$ & & & \\
\hline \multicolumn{8}{|l|}{ Education } \\
\hline Basic & 33 & 57,9 & 24 & 42,1 & 0,14 & 0,68 & $0,32-1,17$ \\
\hline Edvanced & 46 & 45,5 & 55 & 54,5 & & & \\
\hline \multicolumn{8}{|l|}{ Working } \\
\hline Yes & 12 & 32,4 & 25 & 67,6 & 0,02 & 2,59 & $1,19-5,62$ \\
\hline No & 67 & 55,4 & 54 & 44,6 & & & \\
\hline \multicolumn{8}{|l|}{ Knowladge } \\
\hline Low & 7 & 46,7 & 8 & 53,3 & 0,79 & 1,16 & $0,40-3,37$ \\
\hline Hight & 72 & 50,3 & 71 & 49,7 & & & \\
\hline \multicolumn{8}{|l|}{ Place of Birth } \\
\hline Privat & 33 & 52,4 & 30 & 47,6 & 0,63 & 0,85 & $0,45-1,61$ \\
\hline Hospital & 46 & 48,4 & 49 & 51,6 & & & \\
\hline \multicolumn{8}{|l|}{ Birth Assist } \\
\hline Midwife & 53 & 55,2 & 43 & 44,8 & 0,10 & 0,59 & $0,31-1,12$ \\
\hline Obsgyn & 26 & 41,9 & 36 & 58,1 & & & \\
\hline \multicolumn{8}{|l|}{ Gestasional Age } \\
\hline Abnormal & 18 & 69,2 & 8 & 30,8 & 0,03 & 0,38 & $0,16-0,94$ \\
\hline Normal & 61 & 46,2 & 71 & 53,8 & & & \\
\hline \multicolumn{8}{|l|}{ Birth Weight } \\
\hline Abnormal & 18 & 85,7 & 3 & 14,3 & 0,00 & 0,13 & $0,04-0,48$ \\
\hline Normal & 61 & 44,5 & 76 & 55,5 & & & \\
\hline \multicolumn{8}{|l|}{ Family Support } \\
\hline No & 3 & 50 & 3 & 50 & 1,00 & 1,00 & $0,20-5,11$ \\
\hline Yes & 76 & 50 & 76 & 50 & & & \\
\hline \multicolumn{8}{|l|}{ IMD } \\
\hline Yes & 24 & 49 & 25 & 51 & 0,86 & 1,06 & $0,54-2,08$ \\
\hline No & 55 & 50,5 & 54 & 49,5 & & & \\
\hline
\end{tabular}

\begin{tabular}{llll} 
Family Support & 0.68 & 1.48 & $0.23-9.74$ \\
Breastfeeding initiation & 0.86 & 2.17 & $0.47-2.45$ \\
\hline
\end{tabular}

The results of logistic regression analysis above show that of the 10 variables (both independent variables and external variables that allegedly associated with exclusive breastfeeding) there are 3 variables that were statistically significant at the neonatal visit, work and neonates. Variable neonates visit with $\mathrm{p}=0.02 \mathrm{OR}$ 0.42 (95\% Cl: 0.21 to 0.88 ) indicates that a complete neonatal visit 0.42 times the risk of neonatal visits incomplete compared to exclusive breastfeeding. Job variable has a value of $p=0.02$ OR $2.88(95 \% \mathrm{Cl}: 1.22$ to 6.81 ) indicates that the mother does not work increases the risk 2.8 times greater than mothers who work on exclusive breastfeeding. neonates variable has a value of $p=0.00$ OR 0.08 ( $95 \% \mathrm{Cl}: 0.02$ to 0.43$)$ indicates that babies born with normal weight have an increased risk of 0.08 times greater than babies born with abnormal body weight on exclusive breastfeeding.

\section{DISCUSSION}

Site selection of the research consideration the high number of births. The selected location has the highest birth rate in Klaten district, assuming the region has a number of infants aged 6-9 months were enough for the research. Coverage of neonates visit is not a consideration in the selection of study sites due to coverage of neonates visit all areas in Klaten district of Klaten district health profile report in 2012 is quite high at more than $90 \%$.

The results of this study showed a significant relationship between neonatal visits to exclusive breastfeeding, this can be due to the standard implementation of neonates visits refers to the Integrated Management guidelines Young Toddlers, where one of them is exclusive breastfeeding counseling (1).

According to the Department of Health notion 
of neonates, the definition of neonates visits is are visits by health workers to the home birth mothers, to monitor and provide health care to mothers and babies. This is not in accordance with the implementation in communities where neonatal visits were undertaken is of visiting mothers and newborns to health services places. Activities carried out most is immunization. So that the actual implementation of neonates visit was not optimal when viewed from the definition, it is probably because they still lack the human resources compared to the patients (1). The reason may be lack of human resource in health services

The number of health workers had increased over the previous year, but the ratio of the community health workers were still not balanced thus affecting the quality of health services. Health personnel needs have not been met, especially at the district level due to budgetary burden employees and have not progressed mobilization of health personnel in accordance with the placement of the health task force (1)

There is a distinctive pattern of exclusive breastfeeding based education, namely the existence of an inverse relationship between exclusive breastfeeding education. The higher the education, the lower exclusive breastfeeding (2). The opinion supports the results of this study showed no significant association between maternal education level with exclusive breastfeeding.

Education can be used as a benchmark in choosing and using health facilities, the higher the education level, the more easily accept and develop knowledge (9).

Work is an activity favored by women, in addition to earning that can meet the basic needs of the family, work is a form of respect for one's self. Work either at home or outside the home that requires leaving the child more than two hours let alone the lack of facilities for breastfeeding and pumping breast milk in the workplace be a factor in the failure of exclusive breastfeeding. Companies, government and private institutions on average give leave for childbirth and breastfeeding about three months, and even then there were taken one and a half months before giving birth, but some are given three months after birth. Certainly, factor into the reason of the return of working mothers not to breastfeed exclusively. This is supported by research conducted by Jager et.al and Tarrant et.al reasons delivered by working mothers do not continue to breastfeed exclusively as far away from the workplace, many time-consuming is not permitted because of the leadership and too busy with work $(10,11)$. Lower working mothers in exclusive breastfeeding compared to housewives or mothers who do not work (12).

Knowledge of breastfeeding and exclusive breastfeeding mothers largely especially in Klaten have good knowledge. But not necessarily a good knowledge of exclusive breastfeeding can change the original behavior is not exclusive breastfeeding be exclusive, because it is caused by multifactorial. Klaten Regency Government fully supports exclusive breastfeeding for implementation, this is evidenced by the issuance of Klaten District Regulation Number seven in 2008 on early breastfeeding initiation and exclusive breastfeeding followed by the Indonesian Government Regulation number 33 of 2012 on exclusive breast milk is the basis incessant promotion about the importance of exclusive breastfeeding.

Mothers who give birth in health facilities are inadequate are more likely to do exclusive breastfeeding compared with that do not labor in health facilities. In addition to adequate facilities, exclusive breastfeeding success seen from the delivery is also influenced by the mother's satisfaction towards service delivery (11). The results of this study indicate all respondents carry out deliveries in health facilities but does not significantly influence exclusive breastfeeding.Childbirth health is not always a factor supporting the sustainability of exclusive breastfeeding, this can be due to a lack of promotion by health workers about exclusive breastfeeding and lactation management. As the results of research proposed by Tan explanation of the importance of breastfeeding and how breastfeeding is right for inpatient post-delivery support the sustainability of exclusive breastfeeding (13).

Data about the baby's weight at birth was obtained from the record books besides the data is also obtained through interviews with mothers. This is consistent with data collection techniques do Riskesdas ie birth weight resources derived from the recognition of the mother is greater than that derived from records or documents (1).

Based on gestational age and birth weight infants when significantly related to exclusive breastfeeding. This can be due precisely to the mother who gave birth to an abnormal baby, be it about a month or more months or birth weight less than normal, even more, attention to the baby. In addition, women get to have a lot of time 
interacting with healthcare longer than babies born at term and normal birth weight.

Research conduct on factors associated with exclusive breastfeeding result that the gestational age significantly related to exclusive breastfeeding with OR $1.9795 \% \mathrm{Cl} 1.12$ to 3.34 . The results showed that of the 614 babies born at a gestational age of more than or equal to 37 weeks, $55.4 \%$ were exclusively breastfed. In accordance with the results of this study of 132 infants born at term ( $\geq 37$ weeks) $53.8 \%$ were exclusively breastfed (14)

\section{CONCLUSION AND RECOMENDATION}

Most of the mothers as many as 82 respondents (51.9\%) had a complete neonatal visit in Klaten. The scope of exclusive breastfeeding in Klaten high enough, it can be seen from the difficulty of obtaining the control group compared with the group of cases. Work is the most influential factor for exclusive breastfeeding compared to other factors. There is the influence of neonatal visits to exclusive breastfeeding in Klaten

\section{For Mom Community}

Knowledge about exclusive breastfeeding mothers in the community has been good, but there are still mothers who did not breastfeed exclusively. Hopefully, the mother can provide mutual support and seek support from various sources so that exclusive breastfeeding can be done successfully.

\section{For Health Center}

Klaten is the first district in Indonesia that actually provide support for exclusive breastfeeding success by issuing exclusive rules about breastfeeding, so that the program can be sustained is necessary to monitor and better documentation of the relevant officers. This suggestion is based on the findings of the documents at the time of the study are not consistent with the actual data in the field.

\section{For Further Research}

This research was carried out quantitative and data on neonatal visits taken only in terms of frequency. For the next study is expected data on neonatal visits can be explored in more detail both in quantity and quality of the implementation of neonates

\section{REFERENCES}

1. Depkes (2010) Riset Kesehatan Dasar Tahun 2010. Departemen Kesehatan Republik Indonesia. Jakarta.

2. Depkes (2011) Profil Kesehatan Indonesia Tahun 2010. Departemen Kesehatan Republik Indonesia. Jakarta.

3. Menkes (2012) Survey Demografi dan Kesehatan Indonesia 2012. Badan Pusat Statistik Badan kependudukan dan Keluarga Berencana. Kementrian Kesehatan Republik Indonesia. Jakarta.

4. Depkes (2012) Profil Kesehatan Indonesia Tahun 2011. Departemen Kesehatan Republik Indonesia. Jakarta.

5. Saroyo, Y.B. (2009) Pelayanan Pasca Persalinan Maternal dan Neonatal Terpadu (suatu tinjauan pustaka). Jakarta : Buletin Perinasia Menuju Persalinan Aman dan Bayi baru lahir sehat. Tahun XVI, Nomor 3, Ed Oktober-Desember 2009.

6. Djaja, S., Hapsari, D., Sulistyowati, N., Lolong, D.B. (2009) Peran Faktor Sosio-Ekonomi, Biologi dan Pelayanan Kesehatan terhadap Kesakitan dan Kematian Neonatal. Artikel Penelitian, Majalah Kedokteran Indonesia. Vol: 59. No: 8, Agustus 2009.

7. Roesli, U., Suradi, R. (2008) Manfaat ASI dan menyusui. FKUI. Jakarta.

8. Khamzah, S.N. (2012) Segudang Keajaiban ASI yang Harus Anda Ketahui. Flash Books. Yogyakarta.

9. Sodikin (2006), Determinant Perilaku Suami yang Mempengaruhi Pilihan Penolong Persalinan Bagi Istri. Tesis. UGM. Yogyakarta.

10. Jager, M.D., Hartley, K., Terrazas, J., Merrill, J. (2012) Barriers to breastfeeding-A global survey on why women start and stoping breastfeeding. Eur J Obstetrics \& Gynaecology suplement. www.touchogyn.com.

11. Tarran, R., Younger, K., Pereira, M.S., Kearney, J. (2011) Factors associated with duration of breastfeeding in Ireland : Potential areas for 
improvement. Journal of Human Lactation 27(3) 262-271.

12. Olang, B., Heidarzadeh, A., Strandvik, B., Yngve, A. (2012) Reason given by mothers for discontinuing breastfeeding in Iran. BioMed Central International Breastfeeding Journal 7:7 doi: 10.1186/1746-4358-7-7 http://www. internationalbreastfeeding journal.com/ content/7/1/7.
13. Tan, K.L. (2011) Factors associated with exclusive breastfeeding among infant under six months of age in Peninsular Malaysia. International breasfeeding Journal, 6:2.http:// www.internationalbreastfeedingjournal.com/ content/6/1/2.

14. Aidam, B.A., Perez, R.E., Lartery, A., Aidam, J. (2005) Factors associated with exclusive breastfeeding in Accra, Ghana. Eur J Clinic Nutr, 59(6):789-796. 